\title{
Effect of Cyclooxygenase Inhibition on Retinal and Choroidal Blood Flow during Hypercarbia in Newborn Piglets
}

\author{
TOM STIRIS, CLEIDE SUGUIHARA, DOROTHY HEHRE, RONALD N. GOLDBERG, JOHN FLYNN, \\ AND EDUARDO BANCALARI \\ Department of Pediatrics, Division of Neonatology, and Department of Ophthalmology, Bascom Palmer Eye \\ Institute, Miami, Florida 33101
}

\begin{abstract}
The effect of the cyclooxygenase inhibitor, indomethacin, on choroidal (ChBF) and retinal (RBF) blood flow during hypercarbia was examined in 16 paralyzed and mechanically ventilated piglets less than $8 \mathrm{~d}$ old. The animals were randomly assigned to a control group (mean \pm SEM: $w t, 1.66 \pm 0.1 \mathrm{~kg} ; n=8$ ) that received a placebo infusion or to an indomethacin treatment group (wt, $1.68 \pm 0.2 \mathrm{~kg} ; n=8$ ) that received an infusion of indomethacin $(5 \mathrm{mg} / \mathrm{kg}$ i.v. over $30 \mathrm{~min})$. Baseline $\mathrm{ChBF}$ and RBF were measured using radiolabeled microspheres in room air before and $15 \mathrm{~min}$ after the administration of placebo or indomethacin. Animals were then exposed to 30 min of hypercarbia $\left(6-7 \% \mathrm{CO}_{2}\right.$, arterial $\mathrm{CO}_{2}$ pressure 8$10 \mathrm{kPa}$ ) and measurements were repeated. There were no significant differences in RBF between control $(40 \pm 3 \mathrm{~mL} /$ $\mathrm{min} / 100 \mathrm{~g})$ and indomethacin-treated animals $(40 \pm 3 \mathrm{~mL} /$ $\mathrm{min} / 100 \mathrm{~g}$ ) before administration of placebo or indomethacin. However, RBF decreased significantly in the indomethacin-treated animals $(28 \pm 2 \mathrm{~mL} / \mathrm{min} / 100 \mathrm{~g})$ compared to the control group $(42 \pm 4 \mathrm{~mL} / \mathrm{min} / 100 \mathrm{~g}) 15 \mathrm{~min}$ after administration of placebo or indomethacin. Furthermore, an increase in RBF occurred during hypercarbia in the control group $(86 \pm 6 \mathrm{~mL} / \mathrm{min} / 100 \mathrm{~g})$, but this change was blunted in the indomethacin-treated animals $(33 \pm 5$ $\mathrm{mL} / \mathrm{min} / 100 \mathrm{~g})(p<0.001)$. In contrast, ChBF did not differ significantly between the control and indomethacin groups during the periods studied. These results suggest that the increase in RBF during hypercarbia is at least partially mediated by cyclooxygenase by-products of arachidonic acid metabolism. The change in $\mathrm{ChBF}$ appears to be less influenced by these mediators. (Pediatr Res 31: 127-130, 1992)
\end{abstract}

\section{Abbreviations}

RBF, retinal blood flow

ChBF, choroidal blood flow

CBF, cerebral blood flow

ABP, arterial blood pressure

IOP, intraocular pressure

RA, room air

ROP, retinopathy of prematurity

$\mathrm{PaCO}_{2}$, arterial $\mathrm{CO}_{2}$ pressure

PG, prostaglandin
ROP still remains a major problem in the premature infant. Despite the availability of sophisticated methods for monitoring arterial oxygen and carbon dioxide levels, the incidence of ROP has not been significantly reduced in recent years $(1,2)$.

Although hyperoxia is considered to be a major risk factor in the development of ROP (3), experimental data and clinical studies have also suggested that other factors, such as hypercarbia, may play a role in the development of ROP $(4,5)$. This effect may be predicted by the increased ocular blood flow (6-8) and subsequent increase in oxygen tension found in the vitreous humor during hypercarbia (9). To date, little is known about the mechanisms mediating changes of $\mathrm{RBF}$ and $\mathrm{ChBF}$ during hypercarbia. It has been suggested that cyclooxygenase by-products of arachidonic acid metabolism are important in maintaining normal retinal vascular tone (10).

It is also known that these by-products of arachidonic acid metabolism play an important role in the alterations in blood flow associated with hypercarbia in many organs $(11,12)$. To the best of our knowledge, there are no reports studying the effects of cyclooxygenase inhibition on RBF and ChBF changes during hypercarbia.

The purpose of this study was to determine the role of cyclooxygenase by-products of arachidonic acid metabolism in the regulation of RBF and ChBF during hypercarbia in the newborn piglet.

\section{MATERIAL AND METHODS}

Sixteen piglets $(\leq 7 \mathrm{~d}$ old $)$ were anesthetized with ketamine $(20$ $\mathrm{mg} / \mathrm{kg}$, intramuscularly) and xylazine ( $2 \mathrm{mg} / \mathrm{kg}$, intramuscularly) for surgical procedures. Lidocaine hydrochloride $(0.5 \%)$ was used as the local anesthetic for surgical incisions. The animals were then sedated with chloral hydrate $(100 \mathrm{mg} / \mathrm{kg}$, intraperitoneally), which was repeated $(50 \mathrm{mg} / \mathrm{kg}$, intraperitoneally) every $2 \mathrm{~h}$ throughout the study period. Experimental trials were performed at least $2 \mathrm{~h}$ after administration of ketamine and xylazine.

The left femoral artery and vein were cannulated and used for $\mathrm{ABP}$ and blood gas measurements and infusion of maintenance fluids and drugs. A 3.5 F Argyle catheter (Sherwood Medical, St. Louis, MO) was placed in the left ventricle through the right femoral artery under fluoroscopic guidance and used for microsphere injections. The position of the catheter was later verified by autopsy The right brachial artery was also cannulated and used to withdraw blood at a constant rate to obtain reference blood samples. ABP was measured with pressure transducers (model P23-ID; Gould Instruments, Cleveland, OH) and recorded on a multichannel recorder (model 260, Gould Instruments).

All animals were tracheotomized, and a 4- or 4.5-mm endotracheal tube was inserted. The animals were ventilated with a time-cycled, pressure-limited ventilator (model IV-100B infant
Received March 18, 1991; accepted August 26, 1991

Department of Pediatrics (R-131), P.O. Box 016960, Miami, FL 33101

Supported by the University of Miami: Project New Born. T. S. was supported by the Norwegian Research Council for Science and the Humanities, the Norwegian Royal Caribbean Cruise Line Foundation, and the Norwegian Association for the Blind. 
ventilator; Sechrist Industries, Anaheim, CA) and paralyzed with pancuronium bromide for the duration of the study, using an initial dose of $0.2 \mathrm{mg} / \mathrm{kg}$ i.v. followed by a continuous infusion of $0.4 \mathrm{mg} / \mathrm{kg} / \mathrm{h}$.

Rectal temperature was continuously monitored with a thermistor probe (Yellow Springs Instrument Co., Yellow Springs, $\mathrm{OH}$ ), and skin temperature was maintained at $38.5^{\circ} \mathrm{C}$ by means of a servo-controlled radiant warmer. The animals received an infusion of $5 \%$ dextrose $(6 \mathrm{~mL} / \mathrm{kg} / \mathrm{h})$ throughout the study period.

This study protocol was approved by the Animal Care Committee of the University of Miami and was conducted in accordance with the guidelines of the National Institutes of Health.

Blood flow measurements. RBF, ChBF, and CBF were measured using the tracer microsphere technique (13). Microspheres $(15 \pm 1 \mu \mathrm{m})$ labeled with ${ }^{141} \mathrm{Ce},{ }^{46} \mathrm{Sc}(3 \mathrm{M}$, St. Paul, MN), and ${ }^{113} \mathrm{Sn}$ (NEN, Boston, MA) were administered in random order to each animal. Before injection, the microsphere solution was sonicated and vigorously shaken. Approximately $0.7-1.2 \cdot 10^{6}$ microspheres were injected into the left ventricle over a period of 20-30 s. A reference blood sample was continuously withdrawn from the brachial artery catheter $10 \mathrm{~s}$ before, during, and $60 \mathrm{~s}$ after microsphere injection at a rate of $0.97 \mathrm{~mL} / \mathrm{min}$, using a constant flow rate withdrawal pump (Harvard Apparatus, Millis, MA).

After the final blood flow determination, animals were killed, and the eyes and whole brain were removed. Each eye was dissected, and the retina and choroid were isolated; radioactivity content was counted separately. Radioactivity in the cerebral tissues, eyes, and blood samples was measured using a twochannel gamma counter (model 1191; TM Analytic, Elk Grove Village, IL).

Blood flow to the various tissues was calculated with the equation $\dot{Q}=A_{t} \cdot \dot{Q}_{r} / A_{r}$, where $A_{t}$ and $A_{r}$ were the activities (cpm) in the tissue and reference blood, respectively, and $\dot{Q}_{r}$ was the rate of withdrawal of the blood sample.

Blood flow to each tissue was expressed per $100 \mathrm{~g}$ of tissue. CBF was calculated including the entire brain. All tissues and the reference blood contained more than 400 microspheres except for the retinal tissues, which contained $223 \pm 20$ (mean \pm SEM) microspheres. Cardiac output was calculated from the same equation by substituting $A_{t}$ for the total activity injected. Total activity was calculated from the volume of the stock microsphere solution injected.

Experimental protocol. Sixteen newborn piglets were randomly assigned to either a control $(n=8$; wt, $1.66 \pm 0.1 \mathrm{~kg})$ or indomethacin group ( $n=8$; wt, $1.68 \pm 0.2 \mathrm{~kg})$.

A 30 -min stabilization period was allowed after the animals were paralyzed. Baseline measurements of arterial blood gases, $\mathrm{ABP}, \mathrm{RBF}, \mathrm{ChBF}$, and CBF were performed in room air $\left(\mathrm{RA}_{1}\right)$. The animals were randomly assigned before the start of the experiment to a control group receiving a saline infusion or to a treatment group receiving indomethacin at a dose of $5 \mathrm{mg} / \mathrm{kg}$ i.v. over a 30 -min period. All measurements were repeated 15 $\mathrm{min}$ after the end of the saline or drug infusion while the animals breathed room air $\left(\mathrm{RA}_{2}\right)$. To induce hypercarbia $\left(\mathrm{PaCO}_{2}\right.$ between $8-10 \mathrm{kPa}$ ), a gas mixture of $6-7 \% \mathrm{CO}_{2}$ (balance room air) was delivered via the ventilatory circuit for a period of $30 \mathrm{~min}$. At the end of this period, all measurements were repeated. $\mathrm{Hb}$ concentration and hematocrit were obtained at the beginning and end of the experiment.

Data analyses. Repeated measures analyses of variance was used to compare variables studied between control and indomethacin groups. A $p<0.05$ was considered statistically significant.

\section{RESULTS}

Arterial blood gases and $\mathrm{pH}$ are shown in Table 1. Arterial $\mathrm{O}_{2}$ pressure values remained stable throughout the experiment.
$\mathrm{PaCO}_{2}$ values did not differ within or between groups during $\mathrm{RA}_{1}$ and $\mathrm{RA}_{2}$. As expected, there was a similar increase in $\mathrm{PaCO}_{2}$ levels and a decrease in $\mathrm{pH}$ during hypercarbia in both groups. Arterial blood pressure and cardiac output remained constant throughout the study periods and did not differ significantly within or between groups.

There were no differences in RBF between the two groups in $\mathrm{RA}_{1}$. However, there was a significant reduction in $\mathrm{RBF}$ (from $\mathrm{RA}_{1}$ to $\left.\mathrm{RA}_{2}\right)$ after indomethacin infusion $(p<0.02)$ (Fig. 1). This difference was also statistically significant between groups $(p<0.02)$. During exposure to hypercarbia, the RBF response differed significantly between the control and indomethacin groups $(p<0.001)$. The increased RBF observed in the control group was blunted in the indomethacin group.

ChBF did not differ between the two groups at $\mathrm{RA}_{1}$ and $\mathrm{RA}_{2}$ (Fig. 2). During hypercarbia, the ChBF increased significantly only in the control group.

CBF values were similar in the control and indomethacin groups at $\mathrm{RA}_{1}$ (Fig. 3). However, there was a significant decrease in CBF after indomethacin administration at $\mathrm{RA}_{2}$. During hypercarbia, the CBF increased significantly only in the control group, whereas it returned to baseline in the indomethacin group.

\section{DISCUSSION}

The present study demonstrates that the resting vascular tone of the normal retina and the changes observed during hypercarbia are most likely mediated by cyclooxygenase by-products of arachidonic acid metabolism. This response was also seen in CBF, a finding previously reported by others $(11,12,14)$.

PG appear to be important modulators of retinal vasomotor tone (15-18); their infusion $\left(\mathrm{PGE}_{1}, \mathrm{PGE}_{2}, \mathrm{PGF}_{2 \alpha}\right.$ and $\left.\mathrm{PGI}_{2}\right)$ increases total ocular blood flow (18). Indomethacin administration to newborn piglets decreased the ocular blood flow. This was partially reversed by $\mathrm{PGI}_{2}$, but not by $\mathrm{PGE}_{1}$ and $\mathrm{PGF}_{2 \alpha}$ administration (18). In addition, Bill (10) demonstrated a small but significant decrease in RBF in adult rabbits breathing room air after indomethacin administration. However, in the present study, a more striking decrease in RBF was observed in the indomethacin-treated newborn piglets. The discrepancy in the magnitude of $\mathrm{RBF}$ response to indomethacin administration between the earlier study (10) and ours may be related to the differences in age and species of the studied animals. Furthermore, Chemtob et al. (18) have demonstrated that the majority of PG have vasodilator effects in the newborn period, whereas this does not seem to be the case in adult animals and humans $(19,20)$. However, indomethacin is known to have other pharmacologic effects and to be a cyclooxygenase inhibitor (21-23). It has been shown that indomethacin may act as a calcium antagonist (22) and that it also blocks angiotensin in the rabbit's arteries (21). Because reduction of calcium causes vasodilation $(24,25)$ and angiotensin is a vasoconstrictor $(25)$, it appears that indomethacin administration would most likely result in vasodilation. Therefore, an increase in RBF would be expected, not a decrease as was noted in the present study. Also, indomethacin may act as a free radical scavenger, but this effect is only observed with higher doses of indomethacin than the one used in the present study (26). However, we cannot rule out the possibility that the reduction in RBF after indomethacin infusion may in part be explained by effects other than on PG (27), such as inhibition of histamine release (28) and enhancement of the lipoxygenase pathway $(29,30)$.

Hypercarbia increases RBF $(6,7)$ because of a vasodilation of the retinal vessels $(16,31)$. However, the mechanisms that regulate this vasodilation are not fully known. We hypothesized that the increase in retinal blood flow during hypercarbia is mediated by products of arachidonic acid metabolism. This hypothesis is supported by our results, inasmuch as the increase in RBF during hypercarbia was almost completely eliminated in the indomethacin-treated animals. The blunted RBF response to hypercarbia 
Table 1. Arterial blood gas ( $\mathrm{kPa})$, acid/base, mean $\mathrm{ABP}(\mathrm{mm} \mathrm{Hg})$, and cardiac output $(\mathrm{CO})(\mathrm{mL} / \mathrm{min} / \mathrm{kg})$ measurements during room air baseline $\left(R A_{1}\right)$, repeated after placebo or indomethacin infusion $\left(R A_{2}\right)$, and after 30 min of hypercarbic exposure $\left(C O_{2}\right)^{*}$

\begin{tabular}{|c|c|c|c|c|c|c|}
\hline & \multicolumn{3}{|c|}{ Control $(n=8)$} & \multicolumn{3}{|c|}{ Indomethacin $(n=8)$} \\
\hline & $\mathrm{RA}_{1}$ & $\mathrm{RA}_{2}$ & $\mathrm{CO}_{2}$ & $\mathrm{RA}_{1}$ & $\mathrm{RA}_{2}$ & $\mathrm{CO}_{2}$ \\
\hline $\mathrm{pH}$ & $7.46 \pm 0.02$ & $7.45 \pm 0.01$ & $7.18 \pm 0.01 \uparrow$ & $7.44 \pm 0.02$ & $7.41 \pm 0.02$ & $7.16 \pm 0.02 \dagger$ \\
\hline $\mathrm{PaO}_{2}$ & $11.0 \pm 0.4$ & $11.1 \pm 0.5$ & $10.9 \pm 0.7$ & $10.9 \pm 0.4$ & $10.7 \pm 0.5$ & $10.8 \pm 0.5$ \\
\hline $\mathrm{PaCO}_{2}$ & $4.6 \pm 0.04$ & $4.7 \pm 0.1$ & $8.9 \pm 0.1 \dagger$ & $4.5 \pm 0.2$ & $4.6 \pm 0.2$ & $9.1 \pm 0.1 \dagger$ \\
\hline $\mathrm{ABP}$ & $52 \pm 2$ & $48 \pm 3$ & $51 \pm 2$ & $51 \pm 3$ & $49 \pm 2$ & $52 \pm 3$ \\
\hline $\mathrm{CO}$ & $124 \pm 18$ & $115 \pm 19$ & $126 \pm 21$ & $113 \pm 18$ & $127 \pm 15$ & $136 \pm 16$ \\
\hline
\end{tabular}

$*$ All values expressed as mean $\pm \mathrm{SEM}$. $\mathrm{PaO}_{2}$, arterial $\mathrm{O}_{2}$ pressure.

$\dagger p<0.001\left(\mathrm{RA}_{1}\right.$ or $\mathrm{RA}_{2}$ vs $\left.\mathrm{CO}_{2}\right)$.

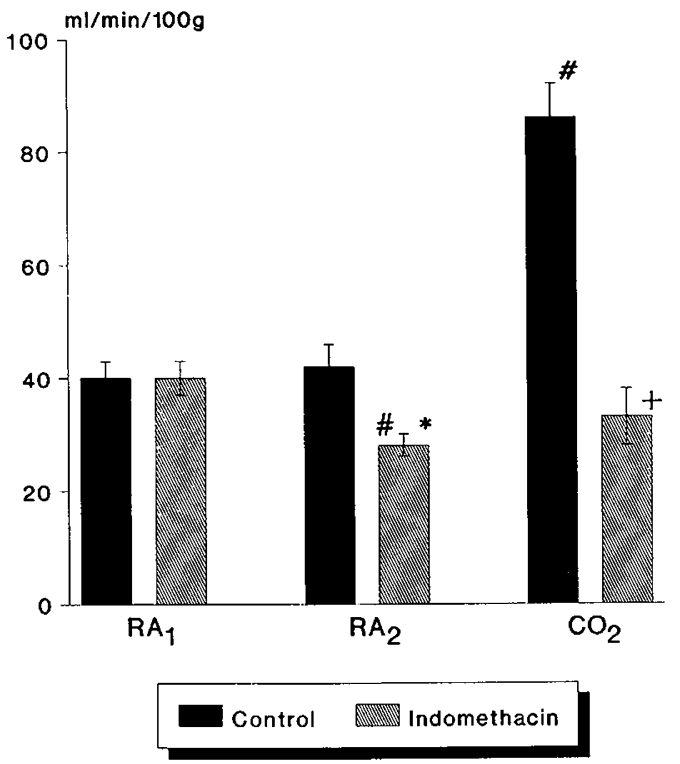

Fig. 1. Changes in RBF at baseline room air $\left(R A_{1}\right)$, after placebo or indomethacin infusion $\left(R A_{2}\right)$, and at hypercarbia $\left(\mathrm{CO}_{2}\right)$. Values given as mean $\pm \mathrm{SEM}$. \#, $p<0.02\left(\mathrm{RA}_{1}\right.$ vs $\mathrm{RA}_{2}$ or $\mathrm{RA}_{2}$ vs $\left.\mathrm{CO}_{2}\right)$; *, $p<0.02,+$, $p<0.001$ (control $v s$ indomethacin groups).

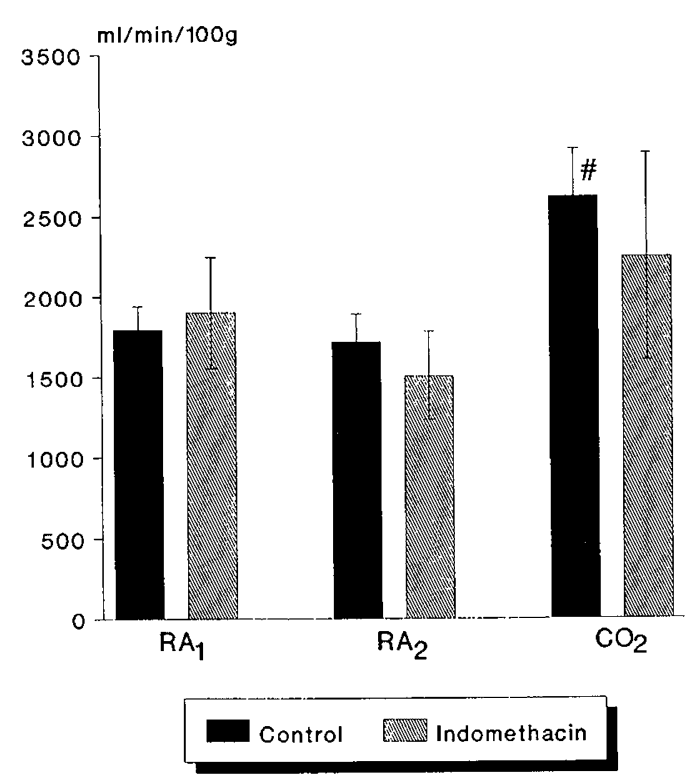

Fig. 2. Changes in $\mathrm{ChBF}$ at baseline room air $\left(R A_{1}\right)$, after placebo or indomethacin infusion $\left(R A_{2}\right)$, and at hypercarbia $\left(\mathrm{CO}_{2}\right)$. Values given as mean $\pm \mathrm{SEM}$. \#, $p<0.05\left(\mathrm{RA}_{2}\right.$ vs $\left.\mathrm{CO}_{2}\right)$.

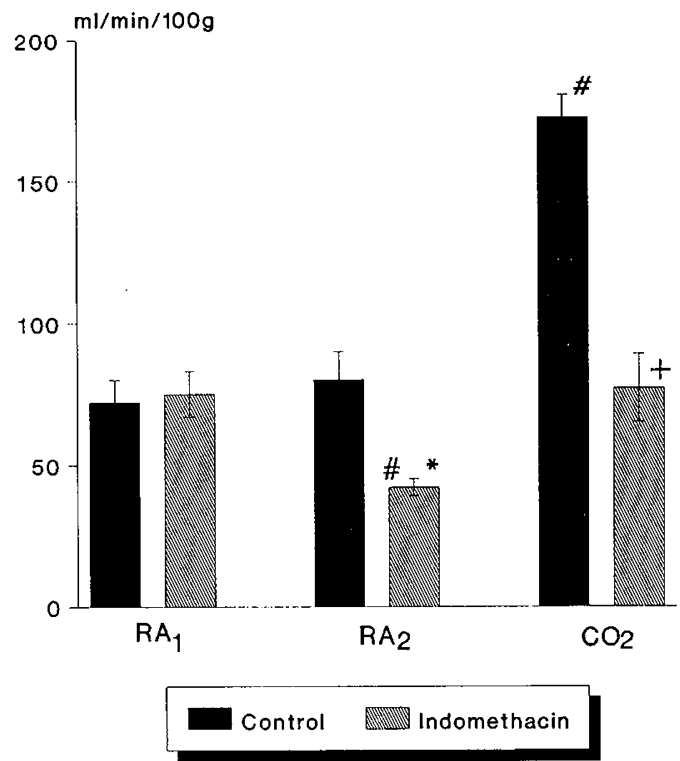

Fig. 3. Changes in $\mathrm{CBF}$ at baseline room air $\left(R A_{I}\right)$, after placebo or indomethacin infusion $\left(R A_{2}\right)$, and at hypercarbia $\left(\mathrm{CO}_{2}\right)$. Values given as mean $\pm \mathrm{SEM}$. \#, $p<0.05\left(\mathrm{RA}_{1}\right.$ vs $\mathrm{RA}_{2}$ or $\mathrm{RA}_{2}$ vs $\left.\mathrm{CO}_{2}\right) ;{ }^{*}, p<0.01,+$, $p<0.001$ (control $v s$ indomethacin groups).

may be attributed to the inhibition of the vasodilator PG products. Supporting the role of PG, Flower et al. (32) demonstrated an increase in prostacyclin production by the retinal endothelium during hypercarbia in neonatal puppies.

Because indomethacin did not cause any change in ChBF in room air-exposed animals, by-products of arachidonic metabolism do not appear to play a significant role in the resting vasomotor tone of the choroid and may be of little importance in modulating the increase in ChBF during hypercarbia. Collectively, our findings suggest differences in the regulation of ChBF and RBF. This difference in $\mathrm{ChBF}$ and $\mathrm{RBF}$ response has been demonstrated previously (6). Retinal and choroidal blood vessel walls have different anatomical structure and innervation (3335). The endothelial cells in the retinal vessels are joined by tight junctions and have basement membranes containing pericytes, characteristics of cerebral vessels, whereas the choroidal vessels walls are fenestrated without tight junctions (33-35). Furthermore, the sympathetic and parasympathetic nervous system regulate ChBF but have little effect on $\operatorname{RBF}(35,36)$.

Although the measurements of $\mathrm{PG}$ levels in the vitreous humor would be desirable, we elected not to do this because repetitive puncture of the eye could change the ocular blood flow.

It is possible that anesthesia and sedation may influence ocular blood flow measurements, but similar doses of anesthesia and sedation were used in both groups, making this factor unlikely as a possible explanation for the differences between groups. IOP changes have only been shown with higher doses of ketamine than used in the present study $(37,38)$. Furthermore, IOP has been shown to return to normal values within $1 \mathrm{~h}$ of drug 
administration. In addition, the half-life of ketamine is $2-3 \mathrm{~h}$, and at least $2 \mathrm{~h}$ were allowed to elapse between the ketamine administration and the first measurements in the study. Neither xylazine nor chloral hydrate have been shown to affect IOP (3941).

Another factor that could have influenced the retinal blood flow measurements was the number of microspheres in this tissue $(13,42)$. However, good reproducibility has been demonstrated in four successive CBF measurements even with an average number of microspheres of 26 per tissue sample (43). Furthermore, Wicker et al. (44) showed that the coefficient of variance of coronary blood flow was 4 and $10 \%$ when both the tissue and reference blood samples contained $>1000$ and $>100$ microspheres, respectively. Therefore, the number of microspheres in the retina in the present study would be within these coefficients of variance.

In conclusion, the data from this study suggest that products of the arachidonic acid metabolism play an important role in maintaining normal resting retinal and cerebral vascular tone and in influencing retinal and cerebral vascular responses to hypercarbia. However, this pathway appears to be less important in controlling vasomotor tone in the choroidal vasculature.

\section{REFERENCES}

1. Bancalari E, Flynn J, Goldberg R, Bawol R, Cassady J, Schiffmann J, Feuer W, Roberts J, Gillings D, Sim E 1987 Influence of transcutaneous oxygen monitoring on the incidence of retinopathy of prematurity. Pediatrics 79:663-669

2. Cats BP, Tan KEW 1985 Retinopathy of prematurity: review of a four-year period. Br J Ophthalmol 69:500-503

3. Lucey JF, Dangman B 1984 A reexamination of the role of oxygen in retrolental fibroplasia. Pediatrics 73:82-96

4. Bauer CR, Widmayer SM 1981 A relationship between $\mathrm{PaCO}_{2}$ and retrolental fibroplasia. Pediatr Res 15:64A(abstr)

5. Tsuchiya S, Tsuyama K 1987 Retinopathy of prematurity birth weight, gestational age and maximum $\mathrm{PaCO}_{2}$. Tokai J Exp Clin Med 12:39-42

6. Stiris T, Odden GP, Hansen WR, Hall C, Bratlid D 1989 The effect of arterial $\mathrm{PCO}_{2}$-variation on ocular and cerebral blood flow in the newborn piglet Pediatr Res 25:205-208

7. Milley RJ, Rosenberg AA, Jones M 1984 Retinal and choroidal blood flows in hypoxic and hypercarbic newborn lambs. Pediatr Res 18:410-414

8. Alm A, Bill A 1972 The oxygen supply to the retina. II. Effects of high intraocular pressure and of increased arterial carbon dioxide tension on uveal and retinal blood flow in cats. Acta Physiol Scand 84:306-319

9. Alm A, Bill A 1972 The oxygen supply to the retina. I. Effects of changes in intraocular pressure and arterial blood pressure and in arterial $\mathrm{PO}_{2}$ and $\mathrm{PCO}_{2}$ on the oxygen tension in the vitreous body of the cat. Acta Physiol Scand $84: 261-274$

10. Bill A 1979 Effect of indomethacin on regional blood flow in conscious rabbit a microsphere study. Acta Physiol Scand 105:437-442

11. Wagerle LC, Mishra OP 1988 Mechanism of $\mathrm{CO}_{2}$ response in cerebral arteries of the newborn pig: role of phospholipase, cyclooxygenase and lipoxygenase pathways. Circ Res 62:1019-1026

12. Leffler CW, Busija DW 1985 Arachidonate metabolism on the cerebral surface of newborn pigs. Prostaglandins 30:811-817

13. Heymann MA, Bruce DP, Hoffman JIE, Rudolph AM 1977 Blood flow measurements with radionuclide-labeled particles. Prog Cardiovasc Dis 20:55-78

14. Pickard J, Tamura A, Stewart M, McGeorge A, Fitch W 1980 Prostacyclin, indomethacin and the cerebral circulation. Brain Res 97:425-431

15. Hudes GR, Weiye L, Rockey JH, White P 1988 Prostacyclin is the major prostaglandin synthesized by bovine retinal capillary pericytes in culture. Invest Ophthalmol Vis Sci 29:1511-1516

16. Pournaras C, Tsacopoulos M, Chapuis CH 1978 Studies on the role of prostaglandins in the regulation of retinal blood flow. Exp Eye Res 26:687697

17. Nielsen PJ, Nyborg NC 1990 Contractile and relaxing effects of arachidonic acid derivatives on isolated bovine retinal resistance arteries. Exp Eye Res 50:305-311
18. Chemtob S, Laudignon K, Beharry J, Rex D, Varma D, Wolfe L, Aranda JV 1990 Effects of prostaglandins and indomethacin on cerebral blood flow and cerebral oxygen consumption of conscious newborn piglets. Dev Pharmacol Ther 14:1-14

19. Mahlberg K, Uusitalo R, Palkama A, Tallberg T 1987 Phospholipase $A_{2}$, leukotriene $\mathrm{C}_{4}$ and prostaglandin $\mathrm{E}_{2}$ levels in aqueous humor of guinea pigs with experimental S-antigen induced autoimmune uveitis. Curr Eye Res 6:321-335

20. Thomas MA, O'Grady GE, Swartz SL 1985 Prostaglandin levels in human vitreous. Br J Ophthalmol 69: 275-279

21. Aboulafia J, Mendes GB, Miyamoto ME, Paiva ACM, Paiva TB 1976 Effects of indomethacin and prostaglandin on the smooth muscle contracting activity of angiotensin and other agonists. Br J Pharmacol 58:223-228

22. Northover BJ 1977 Indomethacin: calcium antagonist. Gen Pharmacol 8:293296

23. Kantor HS, Hampton M 1978 Indomethacin in submicromolar concentrations inhibits cyclic AMP-dependent protein kinase. Nature 276:841-842

24. Wahl M 1985 Local chemical, neural, and humoral regulation of cerebrovascular resistance vessels. J Cardiovasc Pharmacol 7(suppl 3):36-46

25. Ganong WF 1973 Cardiovascular regulatory mechanisms. In: Ganong WP (ed) Review of Medical Physiology. Lange Medical Publications, Los Altos, CA pp 433-442

26. DeGiulio PA, Roth RA, Mishra OP, Delivoria-Papdopoulos M, Wagerle LC 1989 Effect of indomethacin on the regulation of cerebral blood flow during respiratory alkalosis in newborn piglets. Pediatr Res 26:593-597

27. Chemtob S, Beharry K, Barna T, Varma DR, Aranda JV 1991 Differences in the effects in newborn piglet of various nonsteroidal antiinflammatory drugs on cerebral blood flow but not on cerebral prostaglandins. Pediatr Res 30:106-111

28. König W, Brom J, Schönfeld W, Knöller J, Stüning M 1987 Effect of tenoxicam and indomethacin on the release of histamine, prostaglandin $E_{2}$, and leukotrienes from various cells. Arzneim-Forsch 37:296-299

29. Dempsey RJ, Roy MW, Meyer K, Cown DE, Tal HH 1986 Development of cyclooxygenase and lipoxygenase metabolites of arachidonic acid after transient cerebral ischemia. J Neurosurg 64:118-124

30. Docherty JC, Wilson TW 1987 Indomethacin increases the formation of lipoxygenase products in calcium ionophore stimulated human neutrophils. Biochem Biophys Res Commun 148:534-538

31. Spalter HF, Teneick RE, Nahas GG 1964 Effect of hypercapnia on retinal vessel size at constant intracranial pressure. Am J Ophthalmol 57:741-744

32. Flower RW, McLeod D, Wajer SD, Sendi GS, Egner PG, Dubin NH 1984 Prostaglandins as mediators of vasotonia in the immature retina. Pediatrics 73:440-444

33. Sigelman J, Ocanizs V 1982 Retina. In: Jakobiac FA (ed) Ocular Anatomy, Embryology, and Teratology. Harper \& Row, Philadelphia, pp 479-506

34. Torozynski E 1982 Choroid and suprachoroid. In: Jakobiac FA (ed) Ocular Anatomy, Embryology, and Teratology. Harper \& Row, Philadelphia, pp $553-585$

35. Bill A 1984 Circulation in the eye. In: Sperelakis RBN (ed) Handbook of Physiology. Williams \& Wilkins, Baltimore, pp 1001-1034

36. Alm A, Bill A 1987 Ocular circulation. In: Moses RA, Hart Jr WM (eds) Addler's Physiology of the Eye. Clinical Application. CV Mosby Co, pp 183203

37. Kiyoshi Y, Yasuichi M 1971 The effect of ketamine on intraocular pressure in children. Curr Res Anesth Analg 50:199-202

38. Schutten WH, Van Horn DL 1977 The effects of ketamine sedation and ketamine-pentobarbital anesthesia upon intraocular pressure of the rabbit. Invest Ophthalmol Vis Sci 16:531-534

39. Ohkubo $\mathrm{H}$, Chiba S 1987 Pharmacological analysis of vasoconstriction of canine ophthalmic and ciliary arteries of alpha-adrenoreceptor agonist. Exp Eye Res 45:263-270

40. Ohkubo $\mathrm{H}$, Chiba S 1987 Vascular reactivity of simian ophthalmic and ciliary arteries. Curr Eye Res 6:1197-1203

41. Judisch GF, Anderson S, Bell WE 1980 Chloral hydrate sedation as a substitute for examination under anesthesia in pediatric ophthalmology. Am J Ophthalmol 89:560-563

42. Buckberg GD, Luck JC, Payne B, Hoffman JIE, Archie JP, Fixler DE 1971 Some sources of error in measuring regional blood flow with radioactive microspheres. J Appl Physiol 31:598-604

43. Nakai M, Tamaki K, Yamamoto J, Shimouchi A, Macoa M 1990 A minimally invasive technique for multiple measurement of regional blood flow of the rat brain using radiolabeled microspheres. Brain Res 507:168-171

44. Wicker PA, Healy BP 1989 Variability of coronary blood flow measurements with microspheres in the rat: role of injection site and sphere number. Cardiovasc Res 23:443-452 